Research Article

\title{
New Diagnosis and Fault-Tolerant Control Strategy for Photovoltaic System
}

\author{
Hassan Abouobaida (D) and Younes Abouelmahjoub \\ Laboratory of Engineering Sciences for Energy (LabSIPE), Chouaib-Doukkali University, EL Jadida, Morocco \\ Correspondence should be addressed to Hassan Abouobaida; hassanabouobaida@gmail.com
}

Received 11 April 2021; Accepted 2 July 2021; Published 21 July 2021

Academic Editor: Huiqing Wen

Copyright (C) 2021 Hassan Abouobaida and Younes Abouelmahjoub. This is an open access article distributed under the Creative Commons Attribution License, which permits unrestricted use, distribution, and reproduction in any medium, provided the original work is properly cited.

\begin{abstract}
This paper discusses open-circuit fault (OCF) diagnosis and fault-tolerant control strategy (FTCS) of a nonisolated DC-DC converter. The photovoltaic power conversion structure (PPCS) consists of a photovoltaic generator and an interleaved Boost converter (IBC). The maximum power point tracking (MPPT) control of the IBC ensures operation at maximum power. The design of the nonlinear Backstepping control is detailed based on the equivalent average model of IBC, and the stability is studied using Lyapunov's theorem. The proposed OCF fault detection is based on sampling the voltage across the inductor at a much higher frequency than the switching frequency. In an OCF situation occurrence and a high control signal state, the detection of three negative samples is a condition for signaling the presence of an OCF fault; the photovoltaic system continues its normal operation. The simulation results show the validity of the proposed FTCS. The proposed diagnosis and control strategy improves the performance of the IBC in terms of cost, reliability, and service continuity.
\end{abstract}

\section{Introduction}

For several years, photovoltaic energy has become one of the most requested renewable energy sources since it is more suitable even in the low levels of irradiation, it is modular, and it has less need for maintenance. Associated with a conditioning circuit based on a DC-DC converter, the applications of the photovoltaic systems are calculators, traffic lights, pumping systems, production plants, and electrification of remote areas [1]. Due to the many advantages of reducing current ripples, limiting the size of passive components, and improving the dynamics due to interleaving mode operation, the interleaving technique is widely used in electric cars, power generation energy, and thermoelectric generation systems [2]. Given their importance in multiple uses of DC-DC converters in several industrial applications, it is necessary to guarantee their reliability through a continuous diagnostic of its operating state. The diagnostic system ensures the reliability of the power converters and thus prevents the propagation of the fault. According to statistics, the majority of failures are related to faults in electrolytic capacitors and power switches $[3,4]$. A significant number of research works deal with fault-tolerant control of these components. The faults of the power switches are classified into two categories, an open-circuit fault (OCF) or a short-circuit fault (SCF). In [5], the authors present an online monitoring method and diagnosis of all components of nonisolated converters (Boost converter, Buck converter, and Buck-Boost). The principle of the OCF fault detection method is achieved by measuring the voltage across the faulty switch which becomes greater than the input voltage. Using the last observation, the author concludes that the monitored switch is faulty. In [6], a fast detection and isolation (FDI) method based on model inversion and fuzzy logic algorithm is presented. The proposed method is validated using a Boost converter, and the simulation and practical results show the validity of the proposed method. The advantages of this method are the fault detection and isolation of a power switch, a sensor, and a capacitor in addition to its robustness with respect to system uncertainties and noise. In [7], the OCF and SCF fault detection method is presented. The analyzed circuit is an $N$-level Buck/Boost converter. The fault detection method uses the flying capacitor voltage and the 


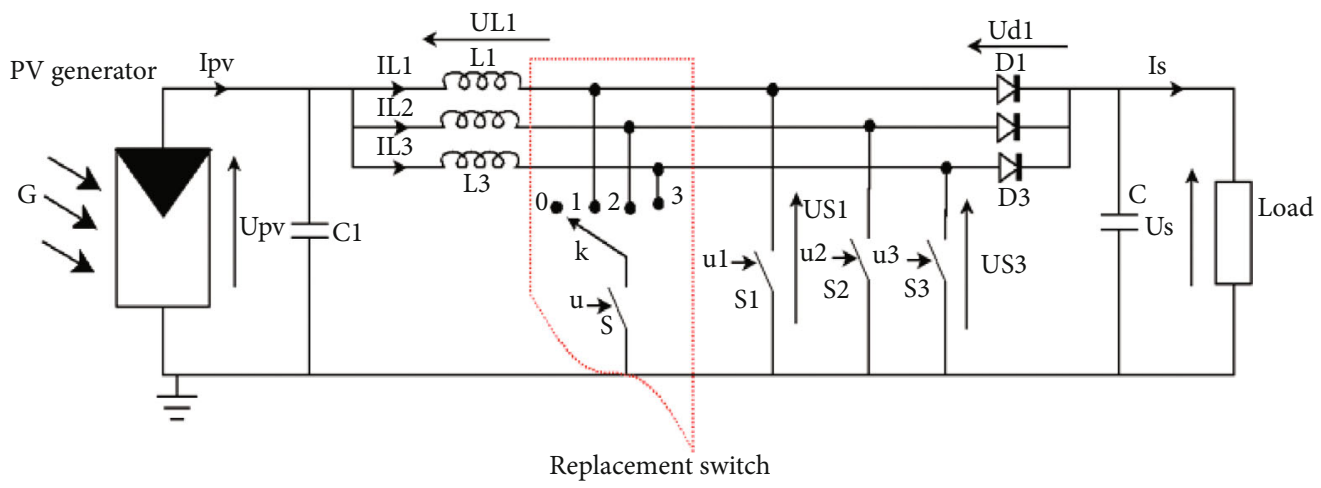

Figure 1: Photovoltaic system based on a three-phase interleaved Boost converter.

current in the inductor. The simulations and practical validation results show the validity of this method. In [8], the author proposes a detection method that is based on the sliding mode observers. The study circuit is a half-bridge DC/AC converter; the sliding mode controller is synthesized through a linear inequality matrix in order to detect the fault. In addition to the accuracy of fault detection, the proposed method has the advantage of rapid identification of system parameters. In [9], the author discusses an OCF in a three-phase interleaved Boost converter. The proposed method is based on the comparison of the input current in the rising edge of the control signal and in the falling edge of this signal. To normalize, the difference between the input current samples at the indicated times divided by the maximum ripple is calculated. The proposed detection strategy has the advantage of the simplicity of implementation without the need for a complex system model or converter emulation. The proposed method allows fault detection in different scenarios, the speed of fault detection $(<2 \mathrm{Tsw})$ compared to the simplicity of the proposed method. The adaptation of the switching frequency allowed good fault detection while reducing the rise effect caused by the fault occurrence. In [10], fast fault detection method (FDM) is discussed in a photovoltaic system based on a Boost converter. The proposed detection method is based on the inductor current shape. The (OCF) detection algorithm is implemented in FPGA, OCF, and SCF and are detected and corrected in real time. The results of HIL and experimental tests show the validity of this method; the detection time is less than a cutting period. In [11], the focus is on monitoring the state of the switch/diode and capacitor. The fault detection method in the indicated components uses two sensors for measuring the voltage of the diode and the inductance and two temperature sensors. Practical validations showed the validity of this method. The proposed method detects the fault for less than one period and it has advantages of simplicity of implementation and the possibility of application in other DC-DC conversion structures (Buck, Boost, and Buck-Boost).

In this paper, a new diagnosis method is proposed. The detection principle is based on sampling the inductance voltage. To ensure rapid detection of OCF, the sampling signal of the voltage across the inductor is characterized by a frequency 10 times equal to the switching frequency of the power switch. In addition, the nonlinear controller synthesis- based Backstepping approach is presented. The stability is studied using the Lyapunov method. The rest of the paper is organized as follows. Section 2 deals with the modeling of the photovoltaic system. A presentation of a Backstepping controller and a proposed OCF detection method are detailed in Section 3. Simulation results and comparative study are presented in Section 4. Section 5 is devoted to conclusions.

\section{Description of the PV System}

Figure 1 illustrates the photovoltaic power circuit. Switches S1 to S3 and S are MOSFETs or IGBTs with antiparallel diodes. The power switch $S$ is a replacement switch in the event of an OCF in one of the S1 to S3 switches, and switch $S$ is used for fault correction in the reconfiguration phase using multiposition switch $\mathrm{k}$.

2.1. Normal Mode Operation. The interleaved DC-DC Boost converter topology is illustrated in Figure 1. The current voltage and power characteristics of the photovoltaic generator are given in Figure 2. Depending on the irradiation level, the power curve is characterized by a point whose coordinates are the maximum power and the corresponding photovoltaic voltage. In normal operations, the interleaved Boost converter is controlled for operation at a maximum power of the photovoltaic source. The power curve shows that the extracted power is maximum if the photovoltaic voltage is close to 31 volts. This remark remains valid for a temperature of $25^{\circ} \mathrm{C}$ despite the changes in irradiation. The curves given in Figure 2 show that the extracted power is intermittent and greatly depends on the irradiation. To maximize the energy extracted independently of climatic changes (irradiation or temperature), an algorithm called (MPPT) is used. The main role of this algorithm is to provide a reference voltage that is used as the desired voltage in the closed control loop. In addition, the DC-DC converter consists of 3 phases that operate in the same way. The power switches are controlled with a phase shift of $120^{\circ}$. The interleaved control technique is adopted to reduce current ripples delivered to the load [12].

2.2. Faulty Mode Operation. In normal operation, in the absence of an (OCF) fault, switch $\mathrm{S}$ is not used. Switch $\mathrm{k}$ has 4 positions. Position 0 represents the rest position (switch not active). In position 1 , this switch is set to replace the 


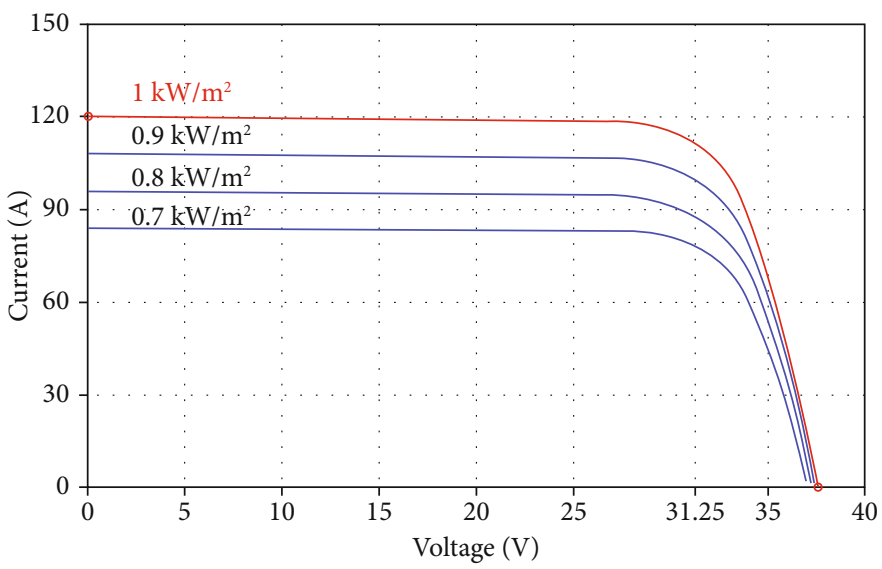

(a)

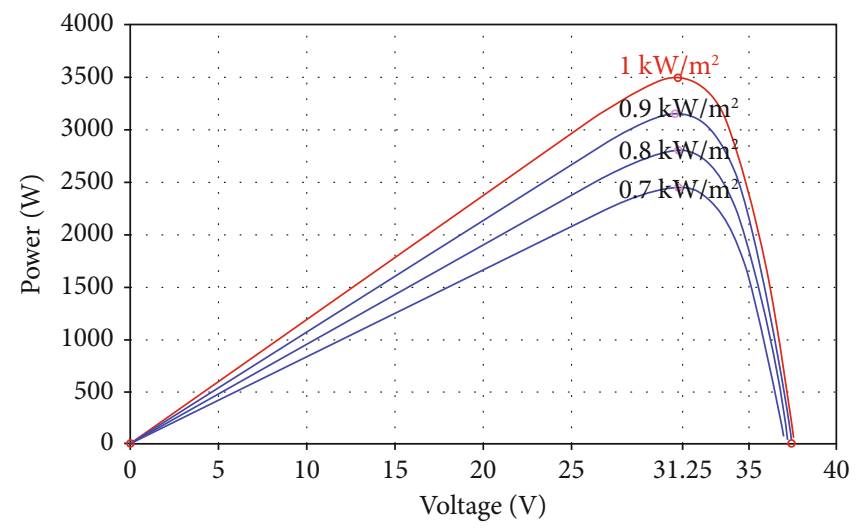

(b)

Figure 2: (a) Current voltage. (b) Power curve of the PV generator.

switch S1 with the replacement switch S when S1 is faulty. Similarly, in positions 2 and 3, this switch is positioned to replace, respectively, the switch S2 or S3 by the switch S if one of these switches is faulty. When an (OCF) occurs in one of the switches $\mathrm{S} 1$ to $\mathrm{S} 3$, the faulty switch is isolated, then replaced by the switch $S$. The emergency switch is then ordered to ensure normal operating continuity of the photovoltaic production system. The major advantage of the proposed structure is that a single correction switch is shared to correct the failure.

2.3. Interleaved Converter Model. The instantaneous DC-DC converter model is given as follows [12]:

$$
\begin{aligned}
C_{1} \dot{U}_{p v} & =I_{p v}-\left(I_{L 1}+I_{L 2}+I_{L 3}\right), \\
L_{1} \dot{I}_{L 1} & =U_{p v}-\left(1-u_{1}\right) \cdot U_{s}, \\
L_{2} \dot{I}_{L 2} & =U_{p v}-\left(1-u_{2}\right) \cdot U_{s}, \\
L_{3} \dot{I}_{L 3} & =U_{p v}-\left(1-u_{3}\right) \cdot U_{s},
\end{aligned}
$$

where $U_{s}$ and $U_{p v}$ are, respectively, the input and output voltage; $I_{L 1}, I_{L 2}$, and $I_{L 3}$ are the inductor currents; $u_{1}, u_{2}$, and $u_{3}$ are, respectively, the binary control signals. The aver- aged model of the IBC can be described by

$$
\begin{aligned}
& \dot{U}_{p v}=\frac{I_{p v}}{C_{1}}-\frac{\left(I_{L 1}+I_{L 2}+I_{L 3}\right)}{C_{1}}, \\
& \dot{I}_{L 1}=\frac{U_{p v}}{L_{1}}-\left(1-\alpha_{1}\right) \cdot \frac{U_{s}}{L_{1}}, \\
& \dot{I}_{L 2}=\frac{U_{p v}}{L_{2}}-\left(1-\alpha_{2}\right) \cdot \frac{U_{s}}{L_{2}}, \\
& \dot{I}_{L 3}=\frac{U_{p v}}{L_{3}}-\left(1-\alpha_{3}\right) \cdot \frac{U_{s}}{L_{3}},
\end{aligned}
$$

where $\alpha_{i}(i \epsilon\{1,2,3\}$ are the duty cycle of the control inputs. The averaged model of the IBC is reformulated as follows [12]:

$$
\begin{gathered}
\dot{U}_{p v}=\frac{I_{p v}}{C_{1}}-\frac{1}{C_{1}}[M]^{T} \cdot\left[I_{L}\right], \\
{\left[\dot{I}_{L}\right]=\frac{U_{p v}-U_{s}}{L}[M]+\frac{U_{s}}{L}[\alpha] .}
\end{gathered}
$$

The inductances are assumed to be identical, $\left(L=L_{1}=\right.$ $L_{2}=L_{3}$ ), and matrices $\left[I_{L}\right],[M],[\alpha]$ are defined as follows: 


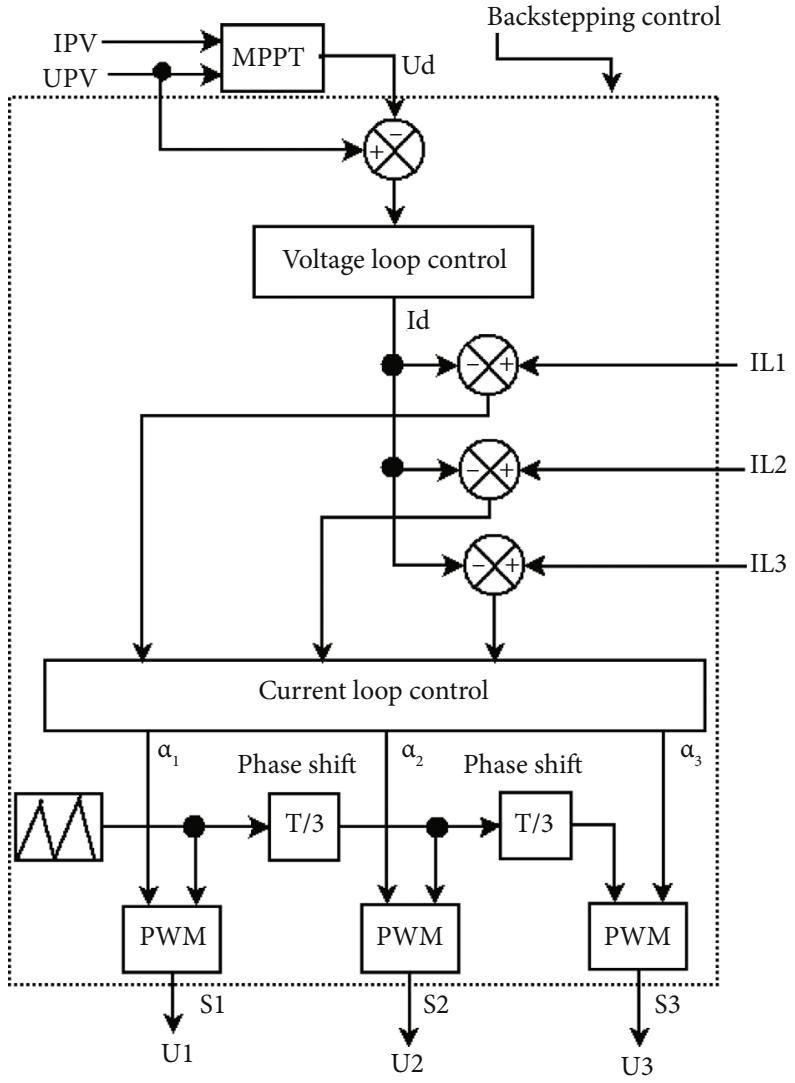

Figure 3: Nonlinear control strategy.

$$
\begin{aligned}
& {\left[I_{L}\right]=\left[\begin{array}{c}
I_{L 1} \\
I_{L 2} \\
I_{L 3}
\end{array}\right],} \\
& {[M]=\left[\begin{array}{l}
1 \\
1 \\
1
\end{array}\right],} \\
& {[\alpha]=\left[\begin{array}{l}
\alpha_{1} \\
\alpha_{2} \\
\alpha_{3}
\end{array}\right] .}
\end{aligned}
$$

\section{Backstepping Control Design}

The Backstepping control approach is a recursive method. It includes feedback control and stability using Lyapunov's theorem. The design process follows steps in which a number cannot exceed the system order. Figure 3 illustrates the IBC control strategy using the Backstepping control loop. The proposed controller synthesis consists of two loops. For operation at maximum power, an external loop is used to regulate the photovoltaic voltage to its reference given by the MPPT algorithm. An internal loop is dedicated to controlling the inductor's currents. The synthesis of the control law is car- ried out in two steps since the IBC model is second order. Between the two steps, a so-called stabilizing function is determined, which subsequently constitutes a reference of the inductor currents [13]. Figure 3 shows a summary of the Backstepping control strategy for the interleaved Boost converter. The Backstepping controller synthesis steps are explained and detailed in the next section.

3.1. Nonlinear Control Design. The control objective is to adjust the photovoltaic voltage to follow its reference.

Step 1. Let us introduce the following output error:

$$
e_{1}=U_{p v}-U_{d}
$$

where $U_{d}$ is the desired photovoltaic voltage. Deriving $e_{1}$ with respect to time yields and accounting for (3) implies

$$
\dot{e}_{1}=\frac{I_{p v}}{C_{1}}-\frac{1}{C_{1}}[M]^{T} \cdot\left[I_{L}\right]-\dot{U}_{d} .
$$

In equation (7), $[M]^{T} \cdot\left[I_{L}\right]$ behaves as a virtual control input. Such an equation shows that one gets $\dot{e}_{1}=-k_{1} \cdot e_{1}$ $\left(k_{1}>0\right.$ being a design parameter $)$ provided that

$$
[M]^{T} \bullet\left[I_{L}\right]=I_{p v}+k_{1} e_{1} C_{1}-C_{1} \dot{U}_{d}
$$




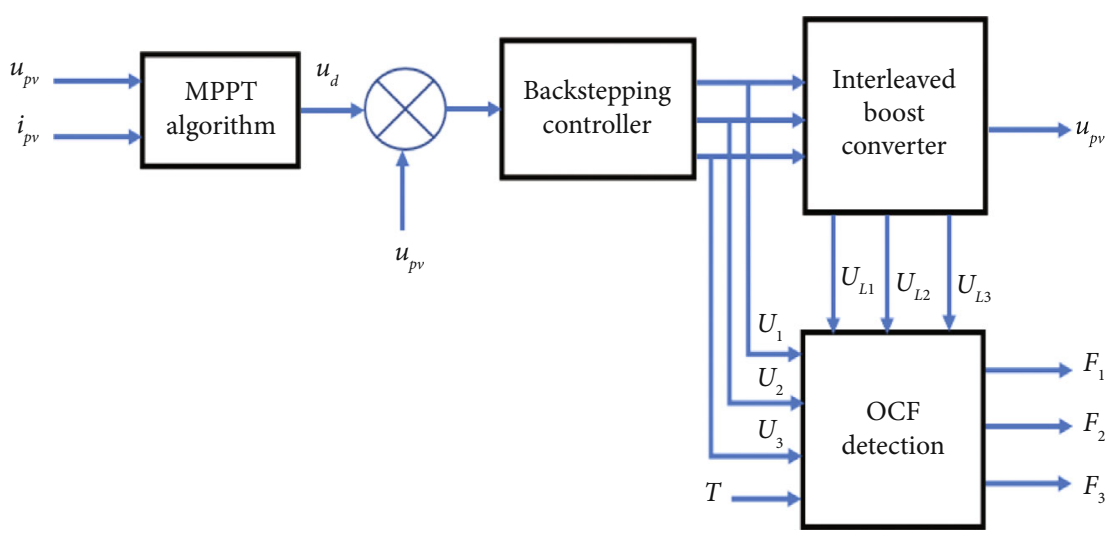

(a)

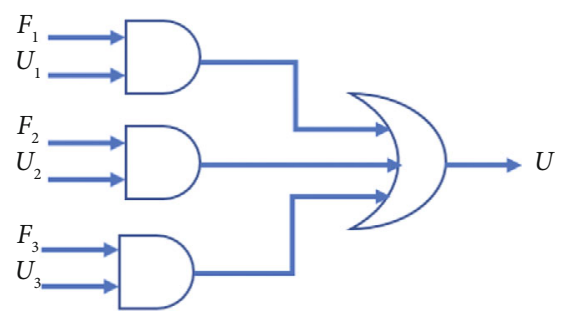

(b)

Figure 4: (a) Closed loop control and fault detection. (b) Control signal for the replacement switch.

As $[M]^{T} \cdot\left[I_{L}\right]$ is just a variable and not (an effective) control input, (7) cannot be enforced at all time instants $t \geq 0$. Nevertheless, equation (8) shows that the desired value for the variable $[M]^{T} \cdot\left[I_{L}\right]$ is

$$
I_{d}=\frac{I_{p v}+k_{1} e_{1} C_{1}-C_{1} \dot{U}_{d}}{3}
$$

Equation (8) is found by supposing that the three phases constituting the IBC converter are identical, and the currents flowing through the inductors have identical reference $I_{d}$. Indeed, the error is expressed by (10)-(11)

$$
[e]=\left[I_{L}\right]-I_{d} \cdot[M],
$$

The error matrix of currents flowing through the inductances is given by (11).

$$
[e]=\left[\begin{array}{l}
e_{11} \\
e_{21} \\
e_{31}
\end{array}\right]=\left[\begin{array}{c}
I_{L 1}-I_{d} \\
I_{L 2}-I_{d} \\
I_{L 3}-I_{d}
\end{array}\right],
$$

where $[e]$ is the error matrix, which vanishes asymptotically; then, the control objective is achieved, i.e., $e_{1}$ vanishes in turn. The desired value $I_{d}$ is called a stabilization function. Now, replacing $\left[I_{L}\right]$ in (8) gives

$$
\dot{e}_{1}=\frac{I_{p v}}{C_{1}}-\frac{1}{C_{1}}\left(e_{11}+e_{21}+e_{31}+3 \cdot I_{d}\right)-\dot{U}_{d}
$$

Replacing (9) in (12) gives

$$
\dot{e}_{1}=-k_{11} e_{1}-\frac{\left(e_{11}+e_{21}+e_{31}\right)}{C_{1}} .
$$

Step 2. Using equation (4), equation (9), and equation (10), the time derivative of the error matrix $[e]$ is as follows:

$$
[\dot{e}]=\frac{U_{p v}-U_{s}}{L}[M]+\frac{U_{s}}{L}[\alpha]-\left(\frac{\dot{I}_{p v}+k_{1} \dot{e}_{1} C_{1}-C_{1} \ddot{U}_{d}}{3}\right) \cdot[M] .
$$

The controlled system is expressed by the time derivative of the errors given by equation (13) and equation (14). Let us choose the Lyapunov function whose time derivative allows asymptotic convergence of errors $\left(e_{1}, e_{11}, e_{21}\right.$, and $\left.e_{31}\right)$ to zero and then deduce the control laws:

$$
V=\frac{e_{1}^{2}}{2}+\frac{e_{11}^{2}}{2}+\frac{e_{21}^{2}}{2}+\frac{e_{31}^{2}}{2} .
$$

The derivative of Lyapunov's function is

$$
\begin{aligned}
\dot{V}= & -k_{1} e_{1}^{2}-k_{11} e_{11}^{2}-k_{21} e_{21}^{2}-k_{31} e_{31}^{2}+e_{11}\left[k_{11} e_{11}-\frac{e_{1}}{C_{1}}\right. \\
& \left.+\frac{U_{p v}-U_{s}}{L}+\frac{U_{s}}{L} \alpha_{11}-\left(\frac{\dot{I}_{p v}+k_{1} \dot{e}_{1} C_{1}-C_{1} \ddot{U}_{d}}{3}\right)\right] \\
& +e_{21}\left[k_{21} e_{21}-\frac{e_{1}}{C_{1}}+\frac{U_{p v}-U_{s}}{L}+\frac{U_{s}}{L} \alpha_{21}\right. \\
& \left.-\left(\frac{\dot{I}_{p v}+k_{1} \dot{e}_{1} C_{1}-C_{1} \ddot{U}_{d}}{3}\right)\right]+e_{31}\left[k_{31} e_{31}-\frac{e_{1}}{C_{1}}\right. \\
& \left.+\frac{U_{p v}-U_{s}}{L}+\frac{U_{s}}{L} \alpha_{31}-\left(\frac{\dot{I}_{p v}+k_{1} \dot{e}_{1} C_{1}-C_{1} \ddot{U}_{d}}{3}\right)\right],
\end{aligned}
$$

where $k_{11}>0, k_{21}>0, \quad k_{31}>0$ are design parameters. Equation (16) shows that the equilibrium $\left(e_{1}, e_{11}, e_{21}, e_{31}\right)=$ $(0,0,0,0)$ is globally asymptotically stable if 


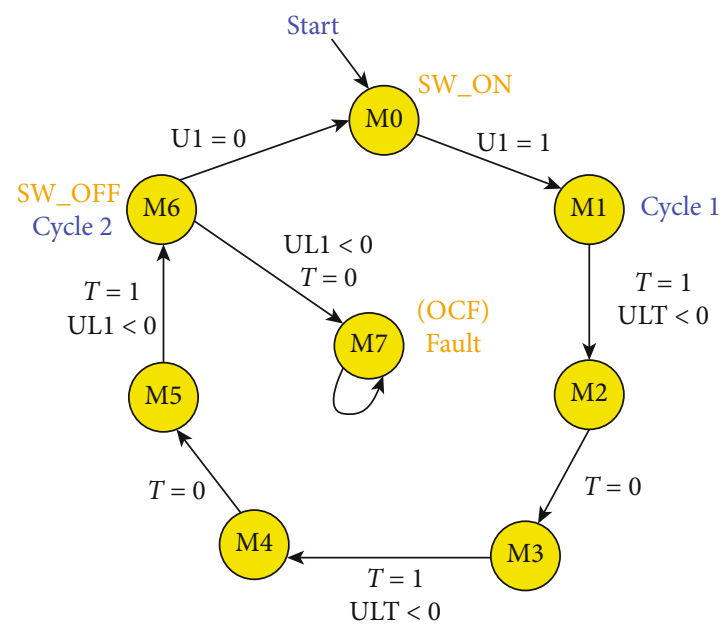

(a)

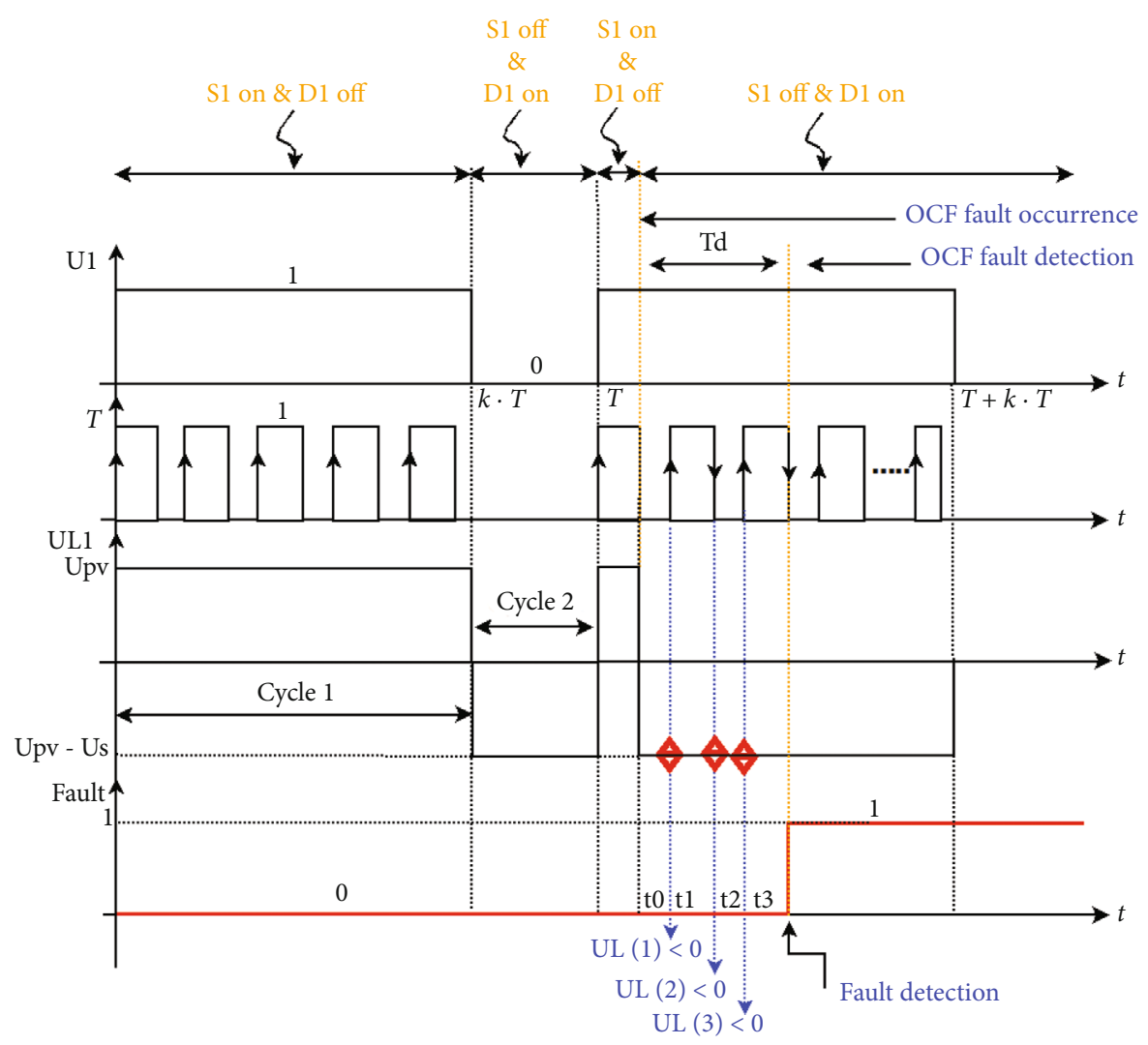

(b)

Figure 5: (a) Proposed (OCF) fault detection. (b) Fault detection timing diagram.

$$
\begin{aligned}
& \alpha_{1}=\frac{L}{U_{s}} \cdot\left[-k_{11} e_{11}+\frac{e_{1}}{C_{1}}-\left(\frac{U_{p v}-U_{s}}{L}\right)+\left(\frac{\dot{I}_{p v}+k_{1} \dot{e}_{1} C_{1}-C_{1} \ddot{U}_{d}}{3}\right)\right], \\
& \alpha_{2}=\frac{L}{U_{s}} \cdot\left[-k_{21} e_{21}+\frac{e_{1}}{C_{1}}-\left(\frac{U_{p v}-U_{s}}{L}\right)+\left(\frac{\dot{I}_{p v}+k_{1} \dot{e}_{1} C_{1}-C_{1} \ddot{U}_{d}}{3}\right)\right], \\
& \alpha_{3}=\frac{L}{U_{s}} \cdot\left[-k_{31} e_{31}+\frac{e_{1}}{C_{1}}-\left(\frac{U_{p v}-U_{s}}{L}\right)+\left(\frac{\dot{I}_{p v}+k_{1} \dot{e}_{1} C_{1}-C_{1} \ddot{U}_{d}}{3}\right)\right] .
\end{aligned}
$$

3.2. Proposed Fault Detection and Correction. Figure 4 illustrates the photovoltaic system in a closed loop. In this paper, the detection study is carried out under the assumption that a single fault occurs or is triggered in one of the switches S1, S2, or S3. The monitoring of the health of the switches S1 to S3 is done by sampling the voltages of the inductances UL1 to UL3 with the signal $\mathrm{T}$ at a frequency 10 times higher than the switching frequency. F1, F2, and F3 represent the binary signals indicating the presence or absence of an OCF in one of the respective switches $\mathrm{S} 1, \mathrm{~S} 2$, and $\mathrm{S} 3$. The replacement 
switch is controlled by the signal of the faulty switch; this signal is deduced from Figure 4(b).

The switches S1 to S3 are monitored in parallel, and simultaneously, each phase is monitored independently of the other phases. On arrival of a rising edge of a control signal $U_{i}$ ( $i$ from 1 to 3 ), the detection process starts in phase $i$. Taking phase 1 as an example, in normal operation, the voltage of the inductance UL1 has a positive sign in the high state of the control. In the presence of an OCF in S1, this rule is no longer valid and the inductance changes to a negative sign. In this paper, and in order to avoid detection errors or confusions about the state of health of the switch S1, three successive inductor voltage UL1 samples of the negative sign in the presence of the high state of the control signal undoubtedly shows that switch S1 is affected by an OCF. Figure 5 illustrates the proposed OCF detection principle using the state machine. The timing diagram presented in Figure 5(b) shows the fault detection process. The following chronogram concerns the detection of a failure that occurs in switch S1 of phase 1. An OCF occurs at time t0, the control signal is in the high state, and the voltage of the inductor switches from a positive value $(\mathrm{UL} 1=\mathrm{Upv})$ to a negative value (UL1 $=\mathrm{Upv}-\mathrm{Us})$. In this situation, after a passage of 3 edges (rising or falling) of sampling signal $\mathrm{T}$, the three successive samples of the inductor voltage UL1 have a negative sign, the variable indicating the presence of a (OCF) is set to high. In conclusion, the three negative samples in addition to the presence of the S1 control signal in the high state confirms that the S1 switch is affected by an OCF.

Table 1 and Table 2 show the maximum detection time according to the following parameters:

(i) The sampling frequency fs $=200 \mathrm{kHz}, 400 \mathrm{kHz}$, and $600 \mathrm{kHz}$

(ii) The number of samples of the $U_{\mathrm{L} 1}$ voltage between 1 and 3 samples

(iii) The duty cycle $\boldsymbol{\alpha}$

The detection time is calculated by assuming that the fault occurs in the opening phase of the power switch. This assumption allows to determine the extreme case and thus to have the maximum detection time. The expression of maximum detection time in the case of one sample, two samples, or three samples of the inductance voltage $U_{\mathrm{L} 1}$ is given by

$$
\begin{gathered}
D T=(1-\alpha) \cdot T+T_{s}, \\
D T=(1-\alpha) \cdot T+1.5 T_{s}, \\
D T=(1-\alpha) \cdot T+2 \cdot T_{s},
\end{gathered}
$$

where $\alpha$ is the duty cycle, $T_{s}$ is the sampling signal period, and $T$ is the switching period.

\section{Simulation Results}

The studied system in the previous sections is simulated under Matlab/Simulink. In addition to the Backstepping
TABLe 1: Maximum detection time $\left(\alpha_{1}=1-\left(U_{p v_{\text {opt }}} / U_{s}\right)=0.54\right)$.

\begin{tabular}{lccc}
\hline $\begin{array}{l}\text { Sampling } \\
\text { frequency }(\mathrm{kHz})\end{array}$ & $\begin{array}{c}\text { Number of } \\
\text { samples }\end{array}$ & $\begin{array}{c}\text { Max detection } \\
\text { time }(\mu \mathrm{S})\end{array}$ & $\boldsymbol{T}_{\boldsymbol{d}} / \boldsymbol{T}(\%)$ \\
\hline \multirow{3}{*}{200} & 1 & 28 & 56 \\
& 2 & 30.5 & 61 \\
& 3 & 33 & 66 \\
\hline \multirow{3}{*}{400} & 1 & 25.5 & 51 \\
& 2 & 26.75 & 53.5 \\
& 3 & 28 & 56 \\
600 & 1 & 24.66 & 49.32 \\
& 2 & 25.5 & 51 \\
& 3 & 26.32 & 52.64 \\
\hline
\end{tabular}

TABle 2: Maximum detection time $\left(f_{s}=10 ; f=200 \mathrm{kHz}\right)$.

\begin{tabular}{lccc}
\hline Duty cycle & $\begin{array}{c}\text { Number of } \\
\text { samples }\end{array}$ & $\begin{array}{c}\text { Max detection } \\
\text { time }(\mu \mathrm{S})\end{array}$ & $\boldsymbol{T}_{\boldsymbol{d}} / \boldsymbol{T}(\%)$ \\
\hline \multirow{3}{*}{0.4} & 1 & 35 & 70 \\
& 2 & 37.5 & 75 \\
\hline \multirow{3}{*}{0.5} & 3 & 40 & 80 \\
\hline \multirow{3}{*}{0.6} & 1 & 30 & 60 \\
& 2 & 32.5 & 65 \\
& 3 & 35 & 70 \\
\hline
\end{tabular}

TABLE 3: Simulation parameters.

\begin{tabular}{lc}
\hline & Parameters \\
\hline PV generator & $P_{p v \_ \text {max }}=3.48 \mathrm{~kW}, U_{p v \_ \text {max }}=31 \mathrm{~V}$ \\
Converter (IBC) & $L_{1}=L_{2}=L_{3}=2 \mathrm{mH}, f=20 \mathrm{kHz}$ \\
& $C=470 \mu \mathrm{F}, C_{1}=3300 \mu \mathrm{F}$ \\
Backstepping & $k_{1}=0.01, k_{2}=10$ \\
PID & $k_{p}=0.1, k_{i}=0.02$ \\
MPPT (P\&O, INC-COND) & Step $=\mathbf{0 . 0 1}$ \\
\hline
\end{tabular}

command, the PID controller, $\mathrm{P} \& \mathrm{O}$, and INC-COND (MPPT) algorithms are implemented to validate the operation of the PV system. Table 3 gives the simulation parameters.

In the following simulation test, an irradiation step $\left(900 \mathrm{~W} / \mathrm{m}^{2}\right.$ to $\left.1000 \mathrm{~W} / \mathrm{m}^{2}\right)$ as illustrated in Figure 6(a) is applied to the PV generator, and the temperature is kept constant at $T=25^{\circ} \mathrm{C}$. Figure $6(\mathrm{~b})$ shows the photovoltaic voltage in the two MPPT cases: P\&O and INC-COND. Figures 6(c) and $6(\mathrm{~d})$ illustrate, respectively, the photovoltaic voltage in transient and at the moment of change of irradiation. It is noted that the maximum power point detection time for both MPPTs is almost identical, equal to $3 \mathrm{mS}$. Regarding the ripple around the maximum point, the INC-COND MPPT 


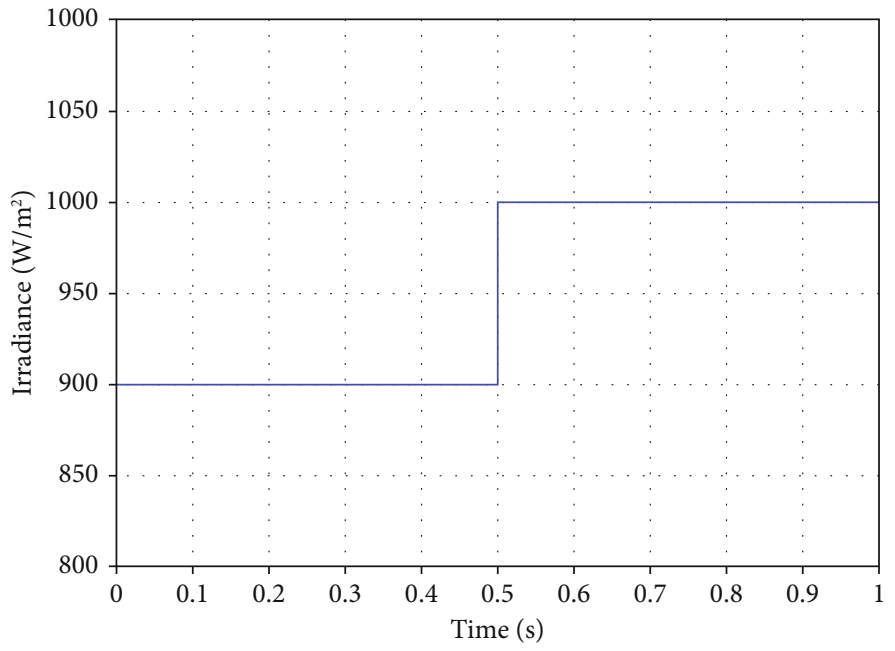

(a)

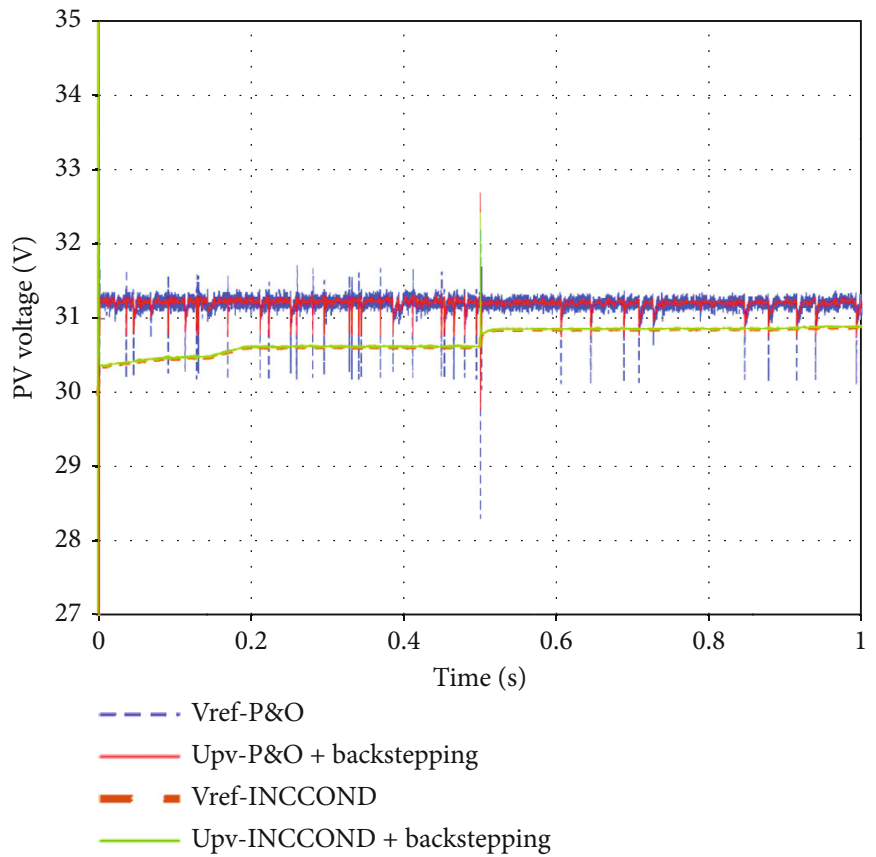

(b)

Figure 6: Continued. 


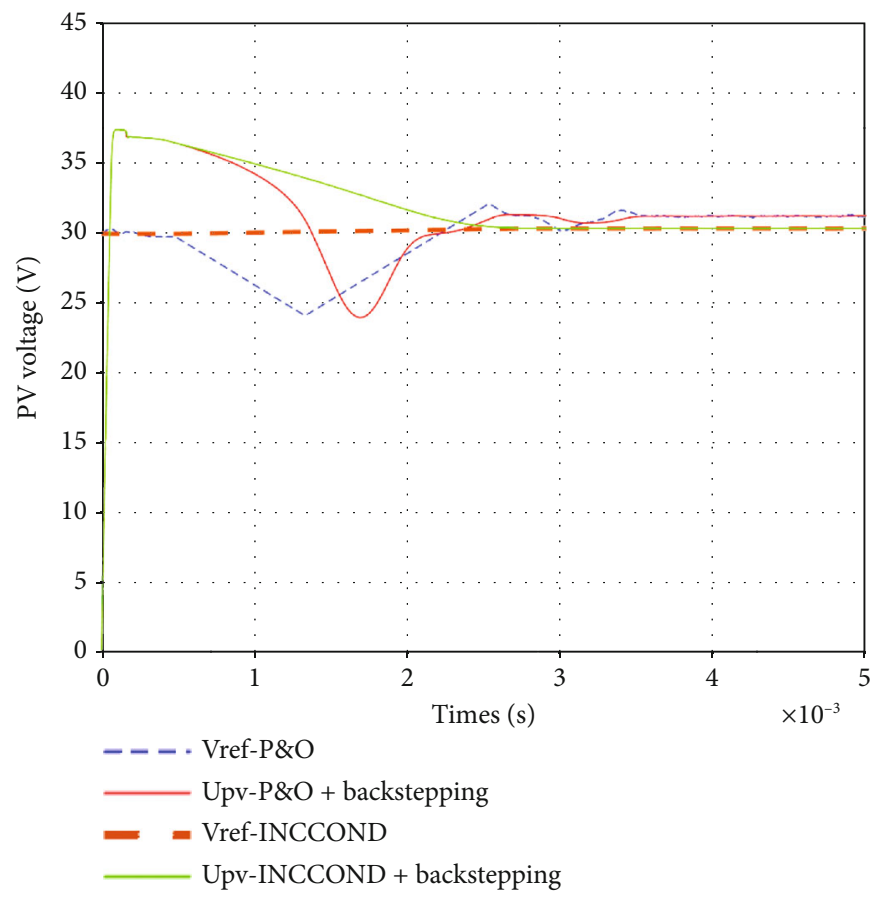

(c)

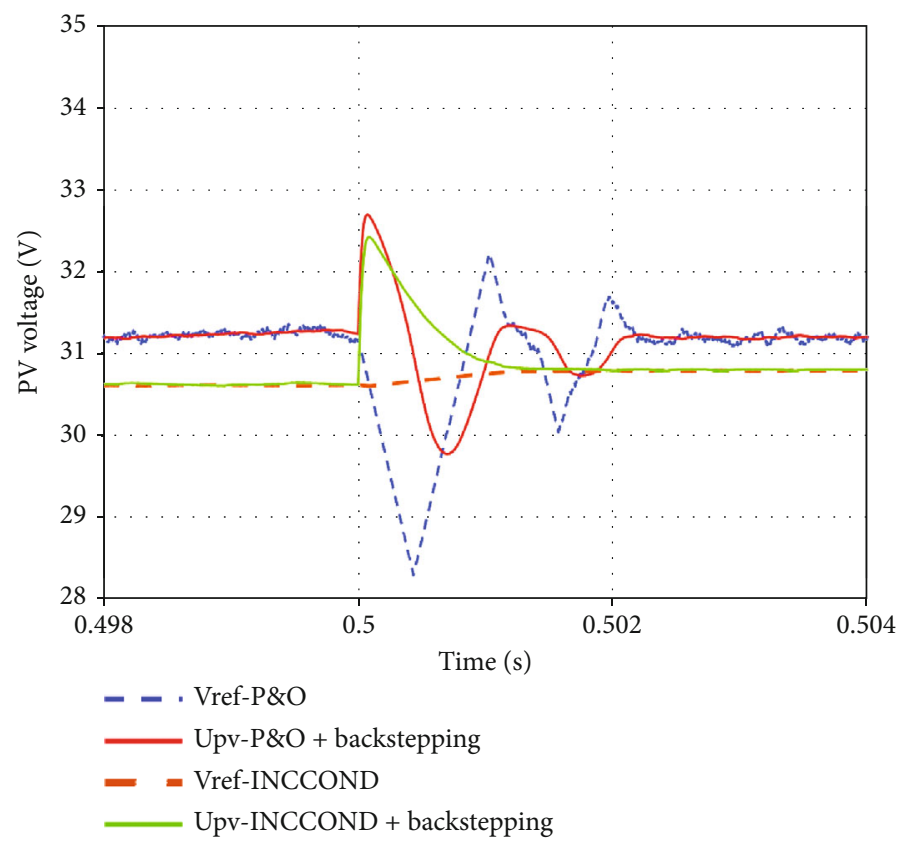

(d)

FIgURe 6: Continued. 


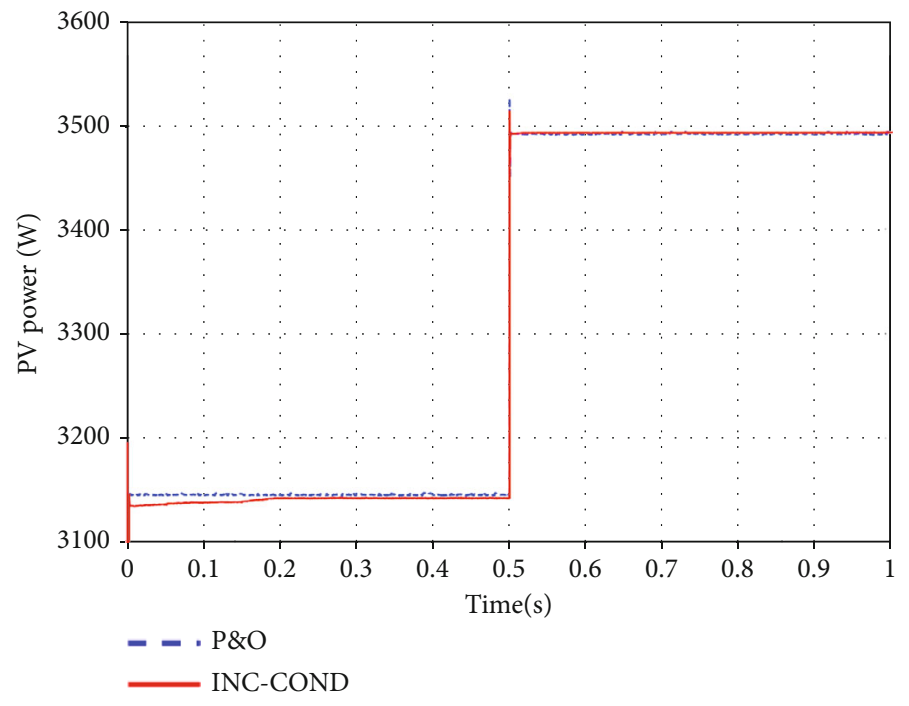

(e)

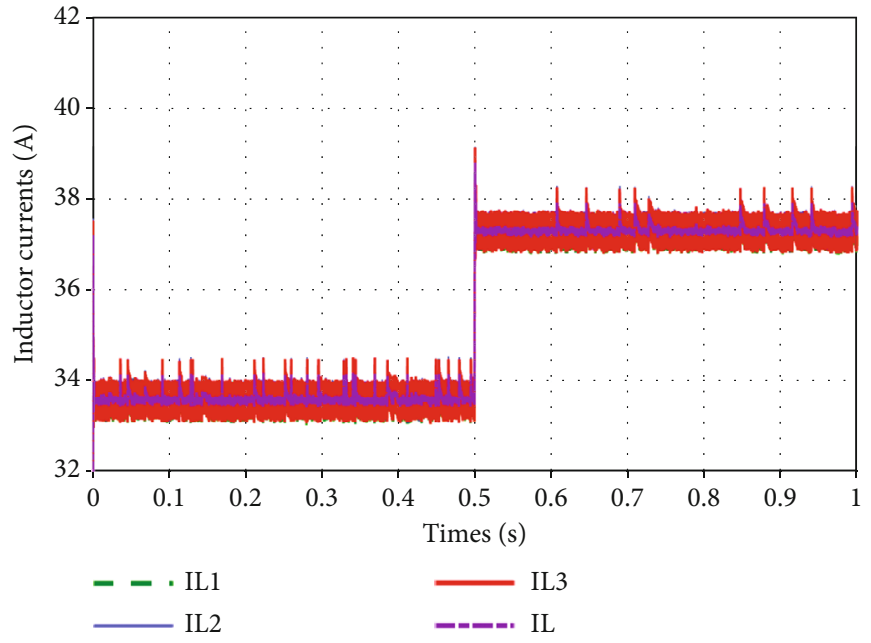

(f)

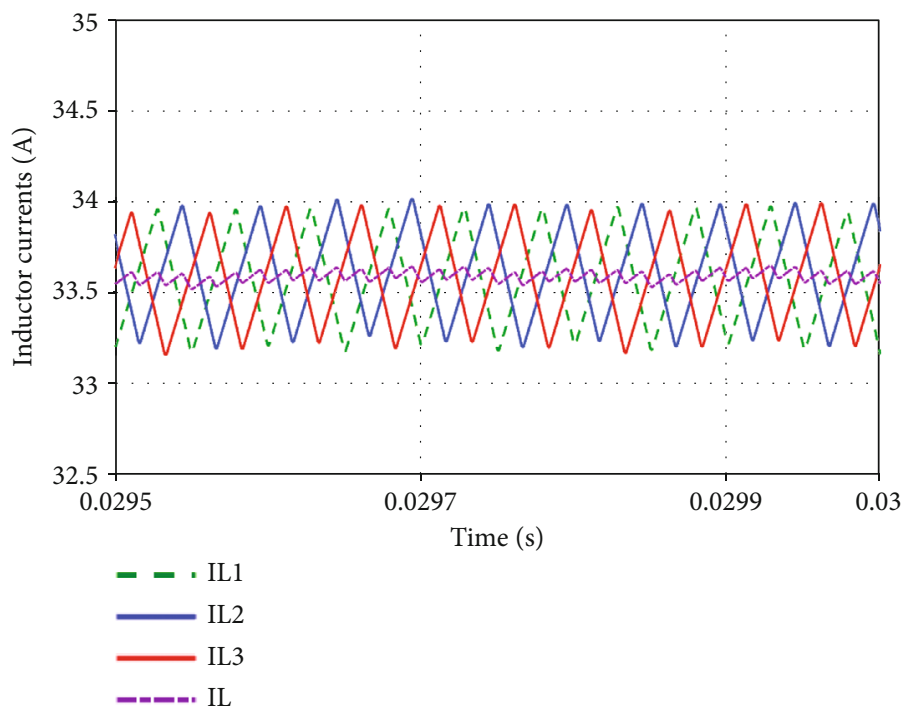

(g)

Figure 6: Continued. 


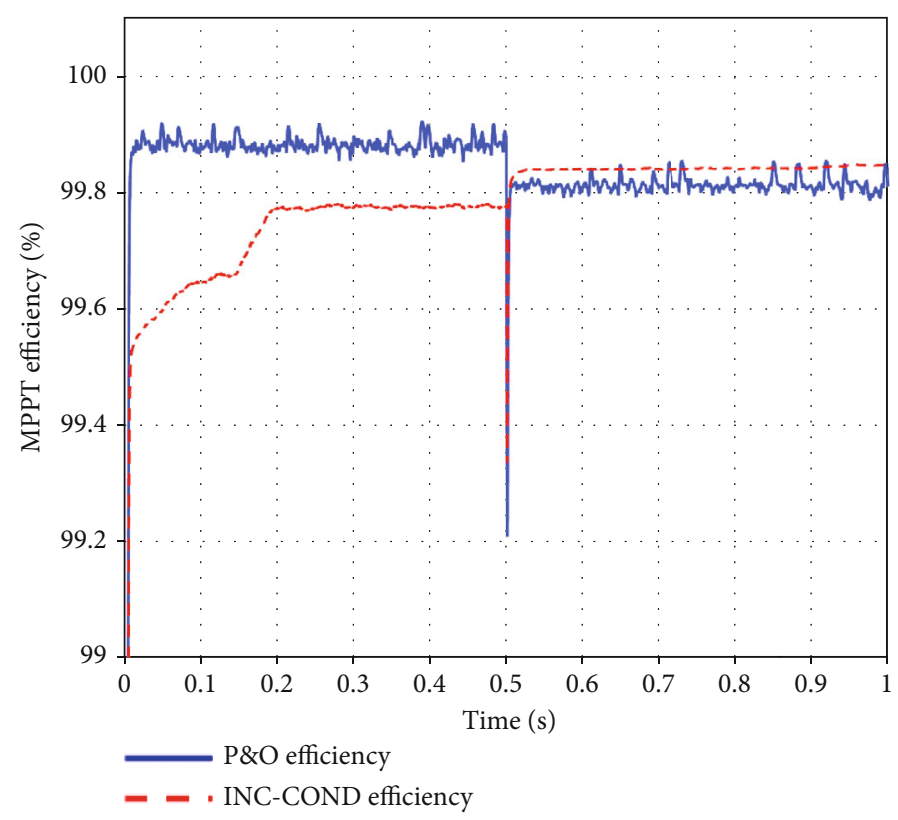

(h)

FIGURE 6: Simulation results of Backstepping and MPPT algorithms: (a) irradiation, (b) PV voltage, (c) PV voltage (0 to $5 \mathrm{mS}$ ), (d) PV voltage (498 mS to $504 \mathrm{mS}$ ), (e) PV power, (f) inductor currents, (g) inductor currents (295 mS to $300 \mathrm{mS}$ ), and (h) MPPT efficiency (\%).

presents small ripples around the maximum point at the beginning of the simulation and also at the moment of irradiation change compared to the P\&O MPPT. Figure 6(e) shows the evolution of the PV power, and it is observed that the extracted power follows its maximum. Figure 6(f) shows the currents flowing through the inductances L1 to L3 and the current IL which represents their addition divided by three. Figure 6(g) shows the interleaving technique applied to a three-phase DC-DC converter that minimizes the ripples of the current IL. Figure 6(h) shows that the efficiency of the MPPTs, the P\&O, and INC-COND MPPTs has an efficiency of $99.8 \%$ when the irradiation is stable. This value drops to $99.2 \%$ at the time of an abrupt change in irradiation.

The following simulation concerns OCF detection as explained in the previous sections. In this simulation, the irradiation is set at $1000 \mathrm{~W} / \mathrm{m}^{2}$ and the temperature is $25^{\circ} \mathrm{C}$. Figures 7 (a) and 7(b) illustrate the photovoltaic voltage and power. It can be seen that the voltage and the power follow their optimum values. At the instant $t=1 \mathrm{~S}$, an OCF is triggered in S1, and a negligible deviation is recorded in the voltage and power. Figure 7(c) shows the signals U1, UL1, and T and the fault detection signal. At the time $t=1 \mathrm{~S}$, an OCF is triggered in S1, and after a time equal to $12.5 \mu \mathrm{S}$, the fault detection signal indicates the presence of a fault. During this phase of detection, it is noted that the voltage of the inductance UL1 has a negative sign which shows that the switch is surely at fault. The samples of UL1 are taken at the rising edge of signal $\mathrm{T}$ which justifies this time of detection. The detection time represents $25 \%$ of the switching period. Once the OCF is detected, the faulty switch is isolated, the correction process is started, and the faulty switch is immediately replaced by the substitution switch $\mathrm{S}$. The photovoltaic system is not influenced by the presence of an OCF, but it continues its normal operation.
In the following simulation test, the studied system is controlled by the Backstepping command and then by the linear command based on a conventional PID corrector. The objective is to make a comparison between these two methods. Identically to the previous simulation, the irradiation is set at $1000 \mathrm{~W} / \mathrm{m}^{2}$ and the temperature is $25^{\circ} \mathrm{C}$. Figure 8(a) shows the photovoltaic voltage given for the two control methods. In the case of a Backstepping controller, it is noted that the response is faster, especially in transient mode; on the other hand, by using a PID controller, the transient mode lasts $0.1 \mathrm{~S}$ so that the voltage returns to the permanent mode. In addition, in the case of a PID controller, the voltage response has an overshoot of 6 volts which corresponds to $19 \%$, unlike the Backstepping control without any overshoot. Figure 8(b) shows the photovoltaic voltage in the interval 0.9 to $1.1 \mathrm{~S}$. At the instant $t=1 \mathrm{~S}$, an OCF in S1 is triggered, a small voltage drop equal to 1 volt is recorded for the Backstepping controller, and the PV voltage quickly returns to its optimal value. The same remark is recorded for the PID controller. The voltage deviation is almost identical to the previous case, but the duration is greater and equal to $50 \mathrm{mS}$. For the extracted power, the same remark as the previous test is recorded. According to Figure $8(\mathrm{c})$, the PV power follows its optimal value, and the response in the case of a Backstepping controller is much better than a PID controller. Figure 8(d) shows the $U_{\mathrm{L} 1}$ inductance voltage in addition to the occurrence and (OCF) detection times. The $U_{\mathrm{Ll}}$ signal evolution is shown when using Backstepping and PID control. It can be concluded that the synthesized controllers (Backstepping and PID) have an influence on the response of the photovoltaic system, but these controls have no influence on the fault detection time, which remains related to the $U_{\mathrm{L} 1}$ signal sampling time. 


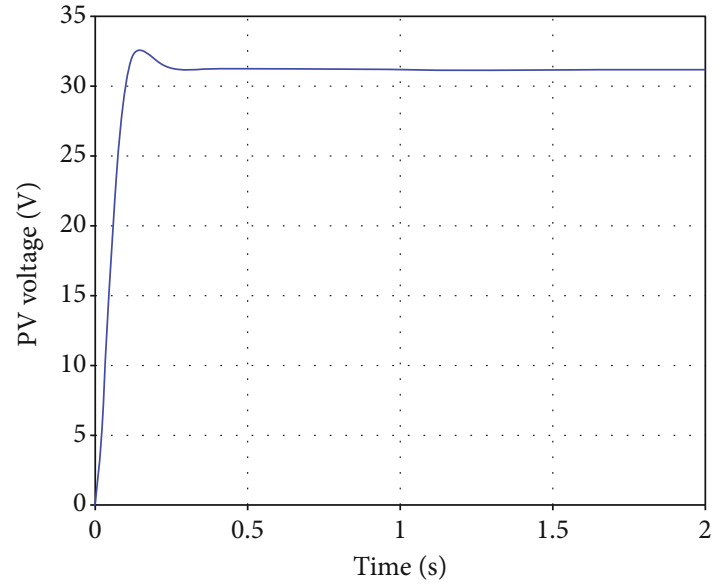

(a)

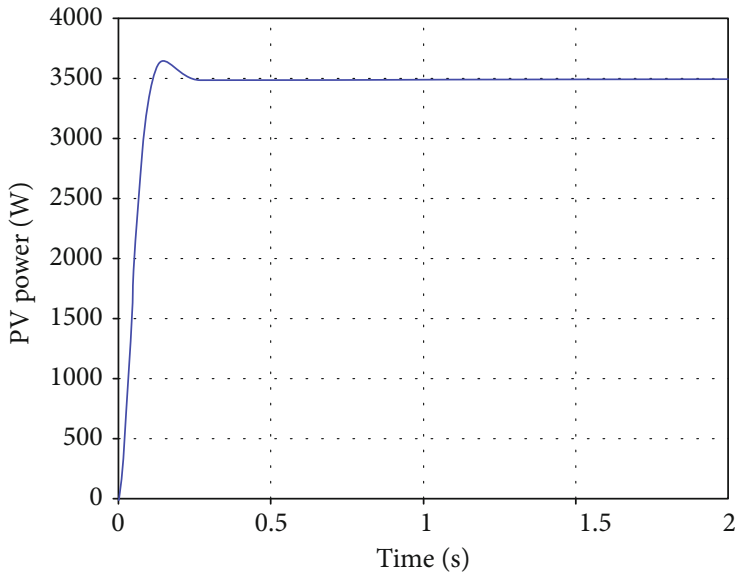

(b)

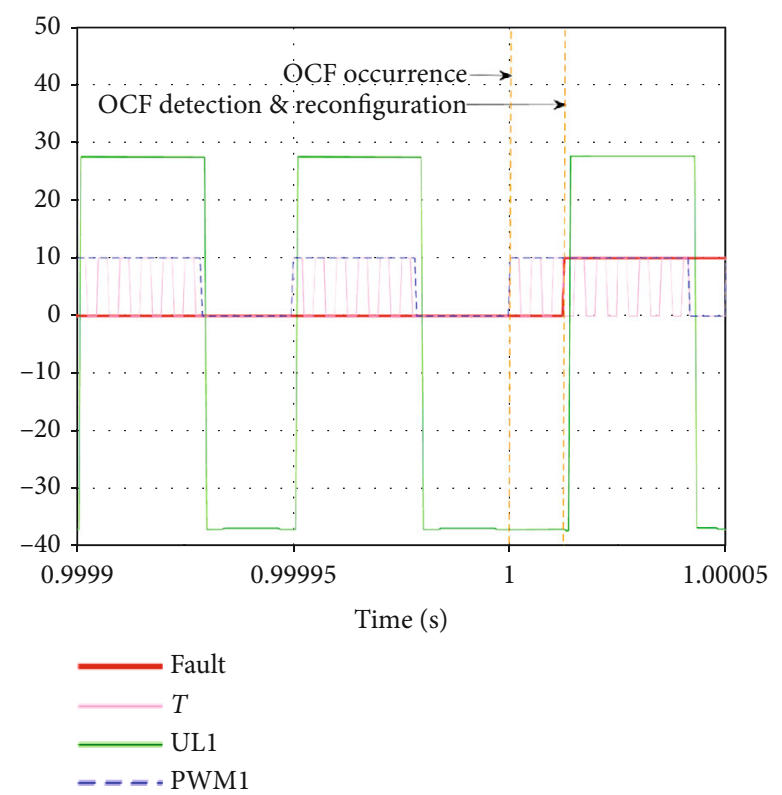

(c)

Figure 7: (a) PV voltage, (b) PV power, and (c) OCF fault detection.

The last simulation in this paper concerns the comparison between the detection method proposed in this paper and the proposed method in [12]. Identically to the previous simulation, the irradiation is set at $1000 \mathrm{~W} / \mathrm{m}^{2}$ and the temperature is $25^{\circ} \mathrm{C}$. In [12], a PID controller is used. According to Figures 9(a)-9(c), a comparison between the commands leads to the same conclusions mentioned above; in summary, the photovoltaic system response in the case of a backstepping controller is better than the response of a PID controller. Likewise, according to Figure 9(d), the OCF detection time that is proposed is more interesting, and it is equal to $12.5 \mu \mathrm{S}$, unlike in [12], where the OCF detection time reaches $50 \mu \mathrm{S}$. The detection time is therefore 4 times greater, equal to the switching period.

Table 4 gives the OCF detection time in some works of the literature. The various simulation results show that the detection time of the proposed method is interesting: the
OCF detection time is improved compared to other methods in the literature.

\section{Conclusion}

In this paper, a new method of OCF detection is exposed. The adaptation circuit consists of a (IBC) is controlled to reduce the ripple of the power transmitted to the load. The maximization of the photovoltaic power is achieved by the implementation of $\mathrm{P} \& \mathrm{O}$ and INC-COND MPPT algorithms. The simulation results showed that the efficiency of the MPPTs is interesting and almost identical; the INC-COND algorithm allows a good optimal point tracking with weak ripples, while the ripples induced by the use of the MPPT P\&O are relatively more important. The adjustment of the PV voltage to the optimum value is obtained by the synthesis of the Backstepping controller, and the stability is analyzed by 


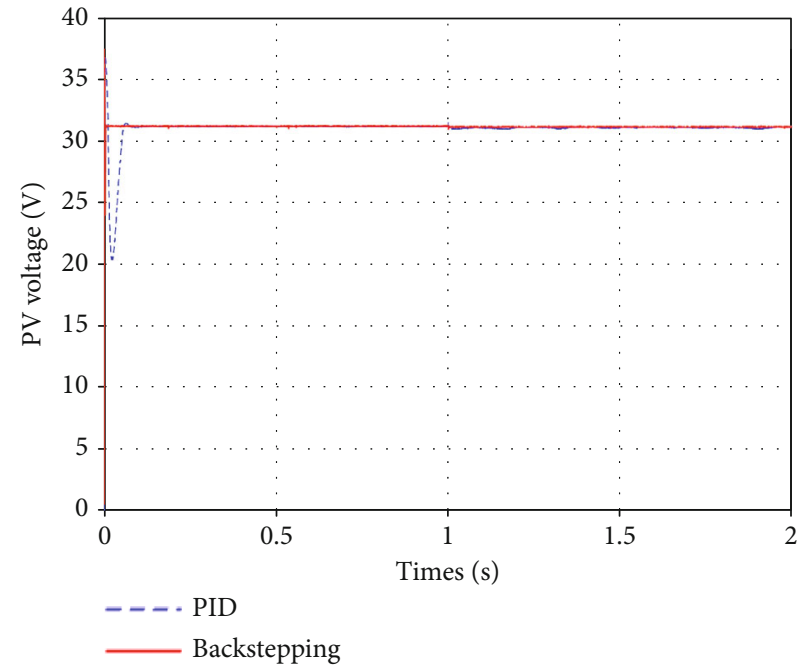

(a)

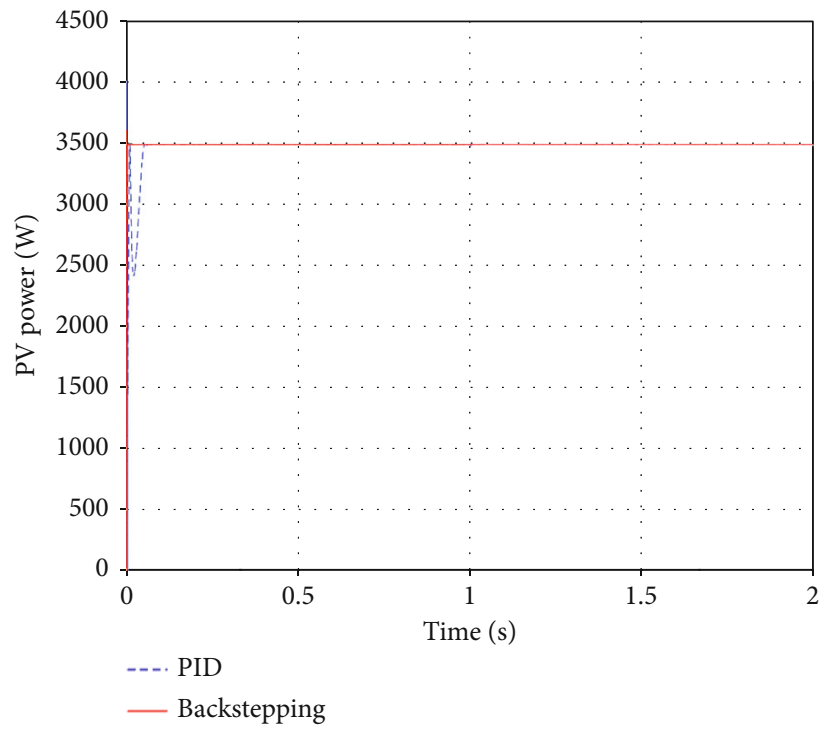

(c)

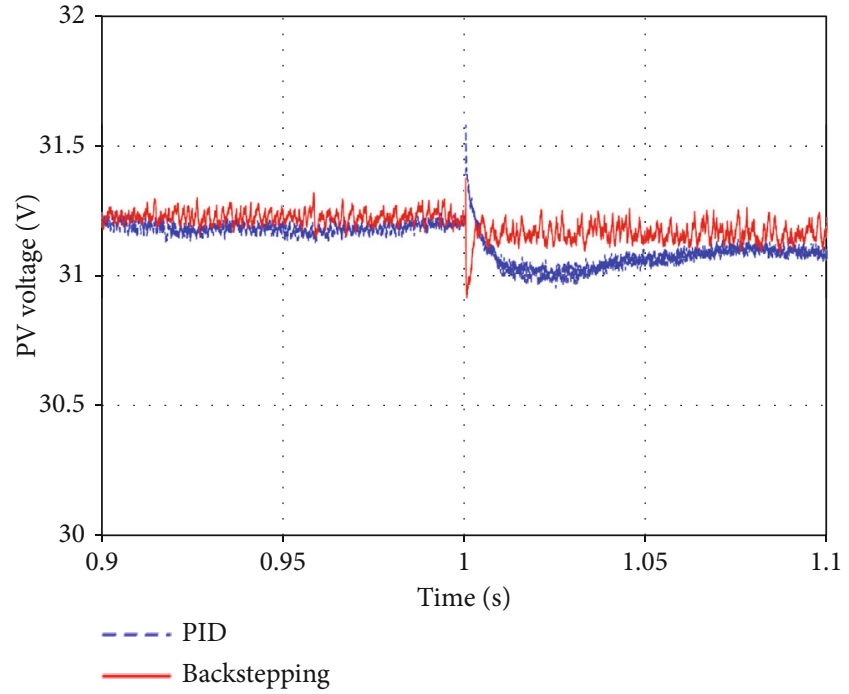

(b)

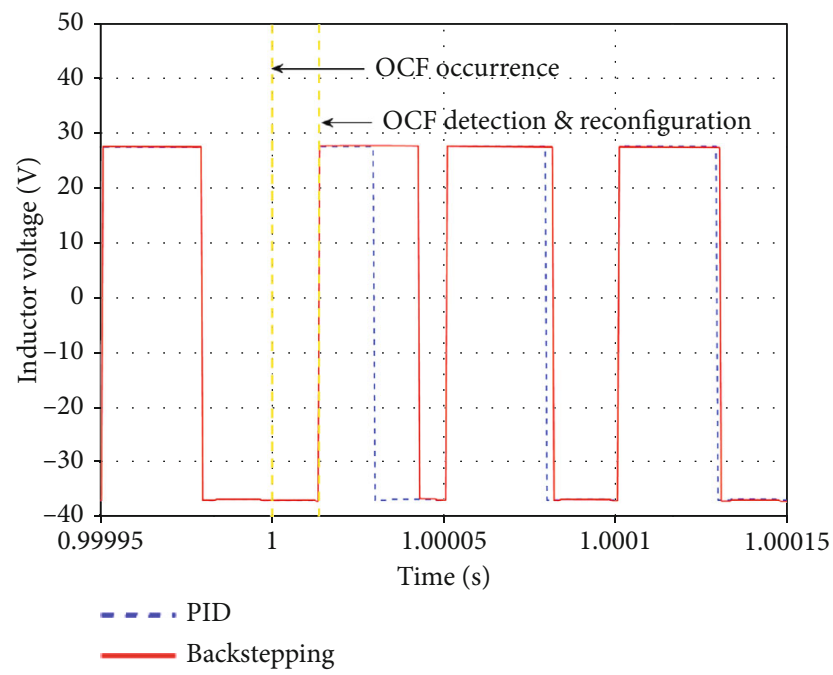

(d)

Figure 8: (a) PV voltage, (b) PV voltage (0.9 to 1.1 S), (c) PV power, and (d) OCF fault detection.

Lyapunov's theorem. The proposed OCF method is based on the use of the state machine; sampling the inductor voltage at a frequency higher than the switching frequency accelerates the OCF detection process. The simulation results show that the OCF detection time is improved compared to other works in the literature; this time, it is less than a switching period. In addition, the Backstepping control allows a much better response compared to the control using a conventional PID controller.

The limitations of the proposed method are related to several factors. A first constraint is the number of samples to be taken from the voltage to decide if there is a fault or not. In this paper, three samples are taken to be sure that there is an OCF in one of the monitored switches. Increasing this number reduces the detection time and improves the reliability of the detection result, and decreasing this number significantly reduces the detection time but can affect the accuracy and reliability of the detection. The duty cycle is the second constraint since the detection time must be strictly lower than the power switch closing time. Another limitation comes from the sampling frequency; this factor is related to the evolution of digital processing circuits (microcontroller, DSP) and which can accelerate the process of fault detection by increasing this frequency. The last criterion is the switching frequency of the power switch. This factor is maintained in this paper since it is linked to the power switch that is a MOSFET. In continuous operation mode, this frequency can be ajusted while respecting the limit values of the passive components (inductance, capacitor) to keep the same current/voltage ripples. By adjusting the switching frequency, the time can be reduced $(1-\alpha) \cdot T$ in equation (18) equation (19), and equation (20)which composes the detection time can be reduced. An increase in the switching frequency allows significantly reducing this term which 


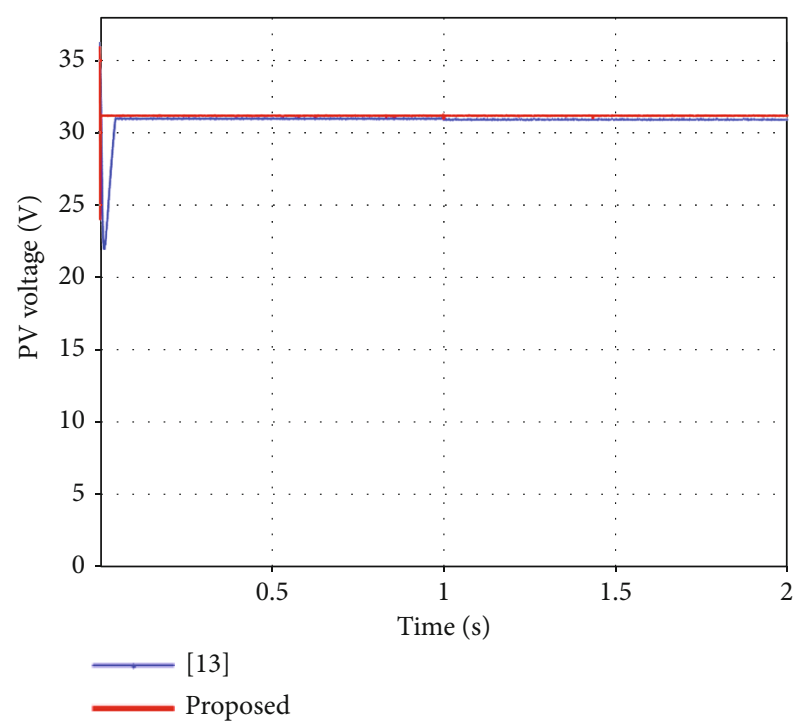

(a)

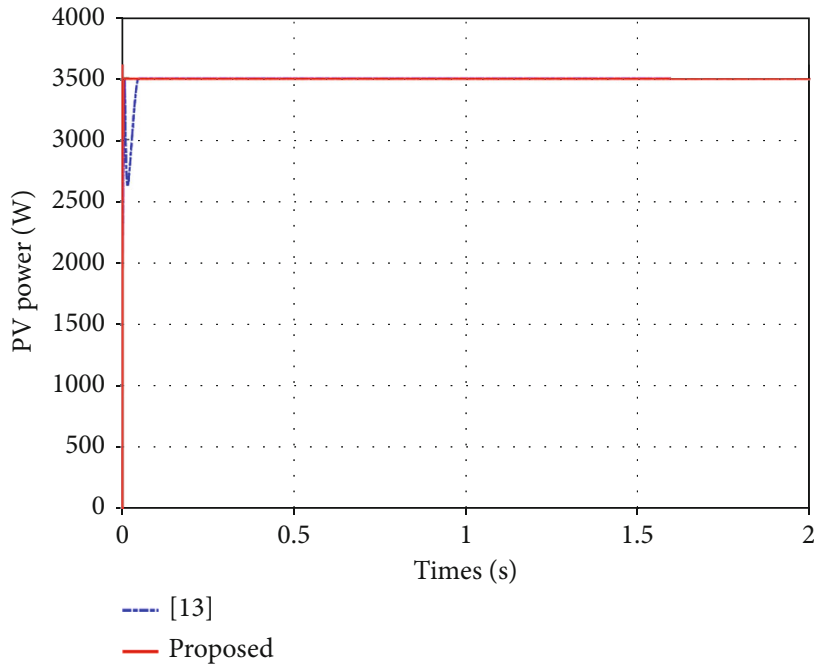

(b)

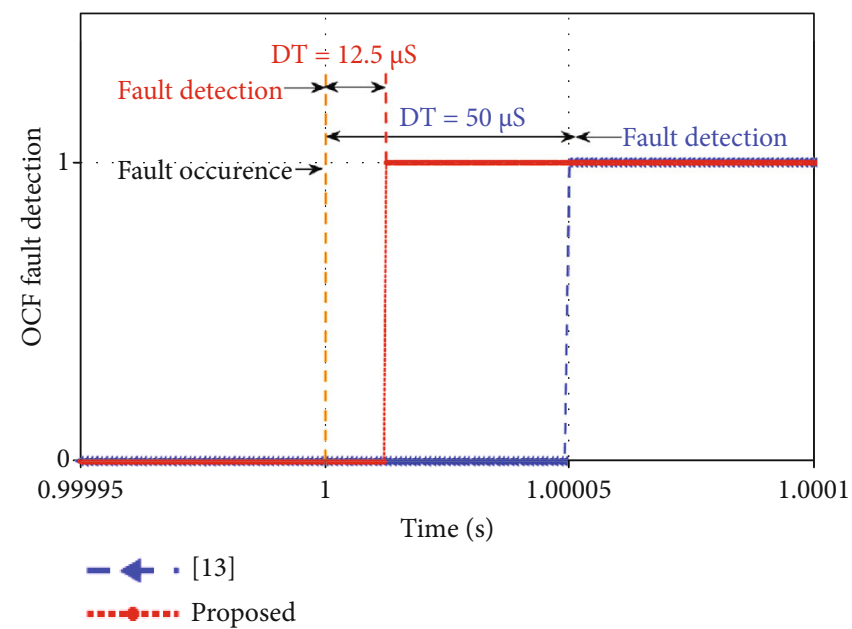

(c)

Figure 9: (a) PV voltage, (b) PV power, and (c) OCF fault detection.

TABLE 4: Detection time comparison.

\begin{tabular}{lc}
\hline Reference & Detection time \\
\hline$[10,12,14,15]$ & $\mathrm{DT} \leq \mathrm{Ts}$ \\
{$[16,17]$} & $\mathrm{DT} \leq 2 \mathrm{Ts}$ \\
{$[18]$} & $\mathrm{Ts}<\mathrm{DT}<2 \mathrm{Ts}$ \\
This paper & $(\mathrm{Ts} / 4) \leq \mathrm{DT} \leq((7 \cdot \mathrm{Ts}) / 10)$ \\
\hline
\end{tabular}

represents an undesirable delay or a waiting cycle and thus a lost time slowing down the detection process since the fault can be triggered when the control signal is in the low state but the detection process starts at the passage to the high state of the control signal.

\section{Data Availability}

No data were used to support this study.

\section{Conflicts of Interest}

The authors declare that they have no conflicts of interest.

\section{References}

[1] E. Ribeiro, A. J. Marques Cardoso, and C. Boccaletti, "Faulttolerant strategy for a photovoltaic DC-DC converter," IEEE Transactions on Power Electronics, vol. 28, no. 6, pp. 30083018, 2012.

[2] H. Wu, V. Pickert, D. Giaouris, and B. Ji, "Nonlinear analysis and control of interleaved boost converter using real-time cycle to cycle variable slope compensation," IEEE Transactions on Power Electronics, vol. 32, no. 9, pp. 7256-7270, 2016.

[3] X. Pei, S. Nie, C. Yu, and Y. Kang, "Open-circuit fault diagnosis and fault-tolerant strategies for full-bridge DC-DC converters," IEEE Transactions on Power Electronics, vol. 27, no. 5, pp. 2550-2565, 2011.

[4] A. O. Di Tommaso, F. Genduso, R. Miceli, and G. R. Galluzzo, "Fault tolerant ancillary function of power converters in 
distributed generation power system within a microgrid structure," Advances in Power Electronics, vol. 2013, Article ID 625130, 2013.

[5] E. Farjah and T. Ghanbari, “A comprehensive monitoring system for online fault diagnosis and aging detection of nonisolated DC-DC converters' components," IEEE Transactions on Power Electronics, vol. 34, no. 7, pp. 6858-6875, 2018.

[6] A. M. Silveiraa and R. E. Araújo, "A new approach for the diagnosis of different types of faults in DC-DC power converters based on inversion method," Electric Power Systems Research, vol. 180, article 106103, 2020.

[7] S. Tang, X. Yin, D. Wang et al., "Detection and identification of power switch failures for fault-tolerant operation of flying capacitor Buck-boost converters," Microelectronics Reliability, vol. 88-90, pp. 1236-1241, 2018.

[8] J. Li, X. Guo, C. Chen, and S. Qingyu, "Robust fault diagnosis for switched systems based on sliding mode observer," Applied Mathematics and Computation, vol. 341, pp. 193-203, 2019.

[9] F. Bento and A. J. Marques Cardoso, "Photovoltaic systems reliability improvement by real-time FPGA-based switch failure diagnosis and fault-tolerant DC-DC converter," IEEE Transactions on Industrial Electronics, vol. 55, no. 5, 2019.

[10] E. Jamshidpour, P. Poure, and S. Saadate, "Photovoltaic systems reliability improvement by real-time FPGA-based switch failure diagnosis and fault-tolerant DC-DC converter," IEEE Transactions on Industrial Electronics, vol. 62, no. 11, 2015.

[11] H. Givi, E. Farjah, and T. Ghanbari, "A comprehensive monitoring system for online fault diagnosis and aging detection of non -isolated DC DC-DC converters components," IEEE Transactions on Power Electronics, vol. 34, no. 7, 2019.

[12] H. Abouobaida, Y. Abouelmahjoub, A. J. Marques Cardoso, H. Chikhy, and S. El Beid, "Open-circuit fault diagnosis and fault-tolerant control strategies for interleaved boost converter," in International Conference on Electronics, Control, Optimization and Computer Science (ICECOCS), Kenitra, 2020.

[13] H. K. Khalil, Nonlinear Systems, Prentice Hall, New York; USA, 1996.

[14] M. Shahbazi, E. Jamshidpour, P. Poure, S. Saadate, and M. R. Zolghadri, "Open-and short-circuit switch fault diagnosis for nonisolated DC-DC converters using field programmable gate array," IEEE Transactions on Industrial Electronics, vol. 60, no. 9, pp. 4136-4146, 2013.

[15] E. Farjah, H. Givi, and T. Ghanbari, "Application of an efficient Rogowski coil sensor for switch fault diagnosis and capacitor ESR monitoring in non-isolated single switch DCDC converters," IEEE Transactions on Power Electronics, vol. 32, no. 2, pp. 1442-1456, 2017.

[16] S. Zhuo, A. Gaillard, L. Xu, C. Liu, D. Paire, and F. Gao, “An observer-based switch open-circuit fault diagnosis of DC-DC converter for fuel cell application," IEEE Transactions on Industry Applications, vol. 56, no. 3, 2020.

[17] K. Ambusaidi, V. Pickert, and B. Zahawi, "New circuit topology for fault tolerant H-bridge DC-DC converter," IEEE Transactions on Power Electronics, vol. 25, no. 6, pp. 15091516, 2010.

[18] M. Gleissner, S. Member, M. M. Bakran, and S. Member, "Design and control of fault-tolerant non-isolated multiphase multilevel DC-DC converters for automotive power systems," IEEE Transactions on Industrials Applications., vol. 52, no. 2, pp. 1785-1795, 2016. 